\title{
Die Gallierrede des Kaisers Claudius 48 n. Chr.: Legitimationsstrategie einer pragmatischen Integrationspolitik
}

\author{
Marvin Becker
}

„... et quod hodie exemplis tuemur, inter exempla erit.“1 Mit diesen Worten beendete der römische Historiograph Publius Cornelius Tacitus die von ihm konzipierte Version der Gallierrede aus dem Jahr 48 n. Chr., die er dem römischen Princeps Claudius in den Mund gelegt hatte. Tacitus griff hier mit den Exempla der Vorfahren ein wichtiges Argument der konservativen römischen Nobilität auf, durch das diese ihr Handeln häufig legitimierte, und ließ es seinen Claudius dafür nutzen, um die Aufnahme von gallischen Notabeln, also eine auf den ersten Blick noch nie dagewesene Neuerung, zu rechtfertigen. Dazu wählte er beispielhafte Episoden aus der römischen Geschichte, die verdeutlichten, dass die Vorfahren selbst ebenfalls Neuerungen zugelassen hatten, die sich im Nachhinein als sehr wichtig für die römischen Erfolge herausgestellt hatten. Damit widersprächen Neuerungen folglich nicht dem mos maiorum, dem für das römische Moralverständnis grundlegenden Wertekanon, sondern seien vielmehr integraler Bestandteil desselben.

$\mathrm{Zu}$ dieser Interpretation kam 2011 auch der Greifswalder Althistoriker Egon Flaig und stellte die von Tacitus konzipierte Rede damit zurecht als eine Quelle vor, die die römische Strategie illustriere, Innovationen mit den überlieferten mores der Vergangenheit in Einklang zu bringen. ${ }^{2}$ Ein Blick auf Flaigs Aufsatzuntertitel „Kaiser Claudius und das römische Selbstverständnis“" sorgt beim kritischen Leser allerdings für Verwunderung, da Flaig offensichtlich außer Acht gelassen hat, dass Tacitus Veränderungen an der Kaiserrede vorgenommen oder sie ohne Kenntnis des Originaltextes der Rede frei konzipiert haben könnte. Die Methodik Flaigs erscheint in diesem Fall durch die Existenz eines sich von Tacitus unterscheidenden Originals der Rede noch unverständlicher. Dieses epigraphisch überlieferte Original war Flaig sogar bekannt, er merkte dazu aber nur lakonisch an, es sei nicht vollständig. ${ }^{3}$ Damit verschwieg er aber, dass die beiden Bronzetafeln, auf denen sich die Redeinschrift befindet, doch in großen Teilen erhalten und deshalb unbestritten die primäre Quelle sind, um festzustellen, welche Argumentationsstrategie Claudius in der geschilderten Situation tatsächlich wählte. Jedenfalls war eine Gleichsetzung des taciteischen Claudius mit dem wirklichen Claudius, wie Flaig sie durch das völlige Aussparen der Originalrede vornahm, ${ }^{4}$ weder durch die Unvollständigkeit der Rede noch durch andere Gründe zu rechtfertigen.

Die Korrektur dieses methodischen Fehlers von Flaig ist ein Anliegen der vorliegenden Arbeit. Dabei kann es aber nicht der Anspruch sein, anhand einer Quelle zu untersuchen, auf welche Art und Weise es die römischen Eliten verstanden, notwendige Neuerungen bei einem grundsätzlich konservativen Selbstverständnis zu legitimieren. Für eine solche Untersuchung wäre ein Vergleich von mehreren Quellen nötig, sodass es schon verwundert, wie Flaig der Meinung sein konnte, dies alleine mit der

1 ,... und was wir heute mit Vorbildern verteidigen, wird zu den Vorbildern gehören.“ (Tac. Ann. XI 24,7). Dieser Arbeit liegt die Edition Cornelius Tacitus, Annalen. Band II, hrsg. und übers. von A. Städele, Darmstadt 2011, zugrunde.

${ }^{2}$ Vgl. Flaig, S. 292.

${ }^{3}$ Vgl. Flaig, S. 288, Anm. 2.

${ }^{4}$ Vgl. Flaig, S. 288-291. 
taciteischen Claudiusrede belegen zu können. Hierbei lag eine klare Überschätzung der Generalisierbarkeit dieser Quelle vor. Vielmehr ist die Rede des Claudius, allerdings die Originalrede, so wertvoll, weil sie überhaupt eines der wenigen Zeugnisse für die politische Meinungsäußerung bezüglich der langsamen Erweiterung des stadtrömischen Senats der frühen Republik zu einer Versammlung von Vertretern der gesamten Reichselite in der hohen und späten Kaiserzeit ist. Außerdem stellt sie das früheste dieser Zeugnisse aus einer Zeit dar, als die Rekrutierung von Senatoren aus den Provinzen jedenfalls noch eher die Ausnahme als die Regel war.

Nun hielt aber der Princeps diese Rede nicht unbedingt als eine Darlegung seines allgemeinen politischen Programms etwa im Stile einer heutigen Regierungserklärung, sondern in der konkreten Situation einer Senatsdebatte, in der er als Censor die Ergänzung des Senats durch eine Gruppe von Adligen aus der Gallia Comata ${ }^{5}$ durchsetzen wollte. Deswegen wird im Folgenden zu prüfen sein, wie diese konkrete Situation beschaffen war und inwieweit die Argumentation aus ihrem unmittelbaren situativen Zusammenhang gelöst als eine allgemeine Legitimationsstrategie der Ergänzung des Senats durch Provinziale aufgefasst werden kann. Auf diese Art wurde sie ja bereits in der Antike von Tacitus gelesen. In diesem Sinne soll also überprüft werden, ob es sich bei der taciteischen Version um eine anachronistische Rückprojektion zu seiner Zeit populärer Legitimationsmodelle in die Zeit des Claudius handelt oder ob es tatsächlich zu so einem frühen Zeitpunkt bereits Legitimationsstrategien für die allmähliche Ergänzung des Senats auch durch provinziale Senatoren gab.

Ließe sich eine solche Strategie feststellen, würde das sicherlich über die Frage Aufschluss geben, ob Claudius während seiner Regierungszeit versuchte, die Anzahl der Provinzialen im Senat gezielt zu erhöhen, und im Sinne der Förderung einer wichtigen Innovation zur nachhaltigen Stabilität des Imperium Romanum als politischer Visionär gelten kann.

Abschließend sollen die Chancen dafür ausgelotet werden, dass die Rede als Beleg dafür gelten kann, dass das Phänomen der steigenden Anzahl provinzialer Senatoren im römischen Senat ein von den römischen Entscheidungsträgern angestoßener und gelenkter Integrationsprozess war, oder ob man von einer bewussten Förderung im Allgemeinen nicht sprechen kann.

Die Anzahl der Zeugnisse zur politischen Legitimation der Einbeziehung von Provinzialen in den Senat ist recht übersichtlich. Während durch Weih- und Grabinschriften noch ungefähr ermittelt werden kann, ab wann vermehrt Senatoren aus der Provinz rekrutiert wurden, ${ }^{6}$ existieren nur wenige Quellen, die etwas über die politische Dis-

\footnotetext{
${ }^{5}$ Gemeint sind hier die drei gallischen Provinzen Aquitania, Lugdunensis und Belgica, die Caesar in seinem „Gallischen Krieg“ als Tres Galliae bezeichnet und die im Gegensatz zur Provinz Gallia Narbonensis im heutigen Südfrankreich gesehen werden müssen. Früher verstand man unter der Gallia Comata (etwa „,behaartes Gallien“ nach der Haartracht seiner Bewohner, im Gegensatz zur Gallia togata im Norden Italiens, wo man sich schon nach römischer Mode kleidete) die gesamte Gallia Transalpina. Vgl. Perl, S. 114).

${ }^{6}$ Die Ergebnisse dieser Forschungen sind in mehreren Studien veröffentlicht worden. Hier seien exemplarisch die Arbeiten von Eck und Alföldy über die Senatoren von Vespasian bis Hadrian bzw. zur Zeit der Antoninen genannt. Darüber hinaus liefert Halfmann eine zeitlich weiter gespannte Zusammenstellung der Senatoren aus dem Osten des Imperiums. Eine vergleichbare Studie für den Westen fehlt bisher, da etwa Freis und Schäfer nur einen kurzen Überblick über die dortige Entwicklung bieten.
} 
kussion $\mathrm{zu}$ dieser Entwicklung sagen. Neben der Claudiusrede, die immerhin als Original und in der ca. 60 Jahre jüngeren Version des Tacitus vorliegt, ist die von Cassius Dio frei erfundene Maecenasrede zu nennen, die aber vor allem Dios Einstellung zur Einbeziehung der Provinzialen darlegt. ${ }^{7}$ Dio aber war ein aus dem Osten stammender Senator des 2./3. Jahrhunderts. Damit stellt der Text also eine relativ späte Quelle dar, die nach der bürgerrechtlichen Gleichstellung der Provinzialen mit den Italikern durch die Constitutio Antoniniana von 212 entstanden ist.

Für das frühe Prinzipat repräsentiert die epigraphische Originalversion der Claudiusrede somit die einzige bekannte authentische Meinungsäußerung einer politischen Führungsperson zur Integration von provinzialen Eliten in den Senat. ${ }^{8}$ Sie ist in vergoldeten Lettern auf zwei Bronzeplatten aufgezeichnet worden. Es handelt sich bei ihr höchstwahrscheinlich um eine Abschrift des senatus consultum, die nach $48 \mathrm{n}$. Chr. im Auftrage der gallischen Ständeversammlung an deren Versammlungsort, dem Augustus-und-Roma-Tempel im pagus condate (Hügel im heutigen Stadtviertel Croix-Rousse) bei Lyon, angebracht wurde. ${ }^{9}$ Die Inschrift ist nicht ganz vollständig, da am oberen Rand der beiden Platten jeweils einige Zeilen fehlen. Der Umfang der Lücken wird überwiegend, wenn auch keineswegs unumstritten, als relativ klein angesehen. $^{10}$

Nicht lange nach seiner Entdeckung im November oder Dezember 1528 in Lyon wurde das epigraphische Original der Claudiusrede Gegenstand historischer Forschungen und bereits 1569 in den in Tacitus' Annalen (XI 24) beschriebenen Sachverhalt eingeordnet. ${ }^{11}$

Seitdem geriet die Rede immer wieder in den Fokus der Forschung, wenn es darum ging, den angeblich recht eigenartigen Charakter des Claudius daran zu überprüfen oder Rückschlüsse auf bürgerrechtliche Strukturen im Imperium Romanum zu

\footnotetext{
${ }^{7}$ Die Rede ist in Cass. Dio LII 14-40 zu finden. Zur Bewertung ihrer Entstehung und historischen Einordnung vgl. Bleicken.

${ }^{8}$ Die Inschrift ist auch bekannt als „oratio Claudii Caesaris“: CIL XIII $1668=$ ILS $212=$ FIRA I $43=$ Smallwood I 369. Im Folgenden soll, wenn der Kontext klar ist, nur die entsprechende Textstelle der Inschrift benannt werden. Die Forschung ist sich darüber einig, dass es sich bei der Inschrift um den Wortlaut der stenographisch festgehaltenen Originalrede handelt. Vgl. etwa Staehelin, S. 166; Griffin (1982), S. 404; Perl, S. 114.

${ }^{9}$ Die gallische Ständeversammlung war eine von Augustus eingerichtete Versammlung aller gallischen Civitates aus den drei gallischen Nordprovinzen, die sich seit 12 v. Chr. einmal im Jahr nahe Lyon, der römischen Kolonie Lugudunum, traf. Sie war u. a. für die Durchführung des Kaiserkultes in den drei Provinzen zuständig und diente wohl als eine Art Kommunikationsplattform der gallischen Gemeinden, die jedoch kaum politisches Gewicht hatte. Genauere Informationen zu diesem concilium Galliarum finden sich bei Deininger, ), S. 99-107, Christopherson und Edelmann-Singer, wobei für die Entstehung des gallischen Provinziallandtages die Seiten 107-109 sehr instruktiv sind. Über die Überlieferungsgeschichte gibt der Fund der Tafeln am Versammlungsort dieses concilium Galliarum Aufschluss, dessen Vertreter wohl mit den ,primores Galliae“ (Tac. ann. XI 23, 1) identifiziert werden dürfen. Vgl. u. a. Riess, S. 212f.

${ }^{10}$ Für sehr große Lücken und sogar eine dritte Tafel trat Vittinghoff, S. 314f., ein. Dieser Ansicht wurde allerdings von vielen Seiten vehement widersprochen. So wurde Vittinghoffs Argument, die dritte Tafel müsse existieren, da dort der Text des Antrags hätte stehen müssen (vgl. ebd.), durch die Gegenthese angezweifelt, dass dieser am verlorenen Anfang der ersten Tafel gestanden hätte. Vgl. dazu u. a. Griffin (1982), S. 408; Schönbauer, S. 169 und Perl, S. 127, der annahm, dass die Anfangslücke tatsächlich nur den Text dieses Senatsbeschlusses enthalte. Diese Vermutung hatte vorher schon Münzer, S. 36, geäußert. Ähnlich: Wellesley, S. 24, der definitiv davon ausging, das Ende der Inschrift sei auch das Ende der Rede gewesen. Bei der Rekonstruktion der relativ kleinen mittleren Lücke warnte er vor einer zu starken Anlehnung an Tacitus (vgl. ebd., S. 19).

${ }^{11}$ Vgl. Wellesley, S. 13. Laut Fabia (1929)S. 29, wurde die Rede 1569 von einem gewissen Vertranius Maurus als erstes mit Tac. ann. XI 24 in Verbindung gebracht.
} 
ziehen. ${ }^{12}$ Darüber hinaus beschäftigten die Forscher neben der Suche nach der richtigen Übersetzung einzelner Passagen, deren Bedeutung sich durch Unvollständigkeit des Textes und die Mehrdeutigkeit der Aussagen nicht mehr lückenlos erschließt, auch zwei diese Untersuchung betreffende Fragestellungen.

Deren erste ist der Vergleich des epigraphischen Originals mit der späteren Umformung des Tacitus, um allgemeine Aussagen über die Zuverlässigkeit der taciteischen Geschichtsdarstellung ableiten zu können. Bezogen auf die Situation um 48 n. Chr., als Claudius die Rede hielt, ist mittlerweile allgemein anerkannt, dass Tacitus hier eine wertvolle Quelle darstellt. Deswegen wird er auch in dieser Untersuchung zur Darstellung des historischen Kontextes der Claudiusrede hinzugezogen, wobei jedoch den Hinweisen, die aus der Inschrift abgelesen werden können, ein klarer Vorrang eingeräumt wird. ${ }^{13}$

Weil Tacitus die Argumentation und den Aufbau der Rede stark veränderte, obwohl oder gerade weil er als Historiker mit Claudius vermeintlich einer Meinung war, ${ }^{14}$ soll sie in der folgenden Untersuchung aber lediglich zur Rekonstruktion der Vorgeschichte der Rede und deren Folgen herangezogen werden. Zur Behebung der Unvollständigkeit des Originals oder zur Interpretation von Claudius' Argumentation soll sie hingegen nicht dienen.

Zweitens wurde darüber gestritten, was genau die Gallier von Claudius erbaten und ob sie das Erbetene dann auch erhielten. Der Hauptgrund für diese Diskussion ist

\footnotetext{
${ }^{12}$ Das Bild von Claudius war lange Zeit sehr negativ geprägt. Die ältere und z. T. auch die jüngere Forschung betrachtete Claudius als vollkommen ungeeignet für die politische Position, die er einnahm. Deswegen sah sie in der nicht immer leicht verständlichen Rede (vgl. Flach, S. 317) mit ihren vielen gelehrtenhaften Wendungen und Gedankensprüngen, vermeintlichen Wutausbrüchen und schlechten Scherzen einen Hinweis für die charakterlichen Schwächen des Claudius. Vgl. dazu Münzer, S. 43; Dessau, S. 159f.; Vittinghoff, S. 312; Griffin (1990), S. 482, 485, 491; Syme, S. 113; Riess, S. 218 und Osgood, S. 166f. Lediglich Wellesley, S. 14f., 32, verteidigte Claudius als Mischung aus Staatsmann und Historiker und verklärte ihn zum politischen Visionär. Sachlicher urteilte auch Albrecht, S. 120124, der nach der Analyse des Stils zu dem Schluss kam, dass die Unterschiede zum geschliffenen Stil des Tacitus gattungsspezifische Gründe hätten, und jedes psychologische Gutachten über Claudius aufgrund der Rede ablehnte (ebd., S. 122f.).

${ }^{13}$ Vereinzelte Verfälschungen der historischen Redesituation ließen sich dennoch finden. So verbanden viele Althistoriker die allgemeine Würdigung von Tacitus als recht zuverlässige Quelle oft mit der Kritik, er habe die Position des Claudius in einem günstigeren Licht dastehen lassen, als sie in der Realität gewesen sei. Vgl. dazu Dessau, S. 160; Wellesley, S. 13f.; Vittinghoff, S. 318f.; Griffin (1982), S. 405-407; Griffin (1990), S. 484, 486; Albrecht, S. 118; Malloch, S. 124-126; Riess, S. 221. Damit sei auch eine Abwertung der Opposition verbunden gewesen, was im Folgenden noch zu beachten sein wird. Hardy (1913), S. 93, betonte, insgesamt sei die Originalrede bei der Untersuchung der Situation von 48 n. Chr. der taciteischen Nachbildung vorzuziehen. Leider sind die Hinweise, die sich aus der Rede herausdestillieren lassen, aber so spärlich, dass man trotz dieser vereinzelten Kritikpunkte auf Tacitus als einzigen Gewährsmann der Ereignisse im Jahr 48 n. Chr. angewiesen bleibt.

${ }^{14}$ Die starken Unterschiede der beiden Reden sind zwar Folge der unterschiedlichen Textgattungen, aber auch des zeitlichen Abstands zwischen ihrer Entstehung. Nur wenige Forscher wollten wie Miller, S. 314f., die Angleichung an den taciteischen Schreibstil als alleinigen Grund für die Veränderungen ausmachen. Häufiger finden sich in der Literatur Vermutungen, Tacitus habe mit seiner Neufassung nicht nur den Aufbau und die Länge, sondern auch die Redeintention verändert. So wäre laut Griffin (1982), S. 411, der Bezug zum konkreten Fall der gallischen Adligen sehr viel schwächer als im Original. Es gehe Claudius aber gerade um diesen speziellen Fall der Förderung von Provinzialen. Schillinger-Häfele (1965), S. 449-453f., bescheinigte Tacitus dagegen zwar, den Streitpunkt der damaligen Debatte gut erkannt zu haben, sah allerdings ein großes Problem darin, dass man eigentlich die bei Tacitus vorangestellten Argumente der Gegner und die Rede des Kaisers als eine Einheit begreifen müsste, die sich schwerlich mit der Originalrede ohne Gegenrede vergleichen lassen würde. Ähnlich urteilte auch Vittinghoff, S. 313.
} 
die ungenaue Auskunft darüber bei Tacitus. Dieser nannte einerseits das ,ius adipiscendorum in urbe honorum" ${ }^{15}$ das die Gallier verlangten, und andererseits das „,senatorum in urbe ius“, ${ }^{16}$ das sie zugebilligt bekamen. An sich wäre dies kein Problem, wenn nicht der Text des Senatsbeschlusses fehlen würde, der am verlorenen Anfang der ersten Kolumne der Originalrede gestanden haben muss. ${ }^{17}$ Dennoch ist jedenfalls die Auffassung der älteren Forschung, die Gallier hätten um die Vervollständigung eines bisher nur unvollständigen römischen Bürgerrechts gebeten, ${ }^{18}$ mittlerweile plausibel widerlegt worden. Stattdessen schwankte die Forschung zuletzt eher zwischen der Bitte um die Verleihung des breiten Purpurstreifens (latus clavus) und dem Ersuchen um die Adlektion (adlectio) einzelner gallischer Stammesführer durch den Kaiser. ${ }^{19}$

In beiden Fällen hätten aber die gallischen primores nicht unter einer rechtlichen Diskriminierung, sondern unter einer Form der sozialen Benachteiligung gegenüber den ritterlichen Eliten Italiens oder der Provinz Gallia Narbonensis im heutigen Südfrankreich gelitten. Zwar waren beide Gruppen Teil der römischen Bürgerschaft und des Ritterstandes. Aber während die italischen und südgallischen Ritter eine

15 „das Vorrecht [...], in der Hauptstadt Ehrenämter zu erhalten“ (Tac. ann. XI 23, 1).

16 „das Recht, in der Hauptstadt Senatoren zu werden“ (Tac ann. XI 25, 1).

${ }^{17}$ Die Alternative dazu wäre die von Vittinghoff, S. 314f., postulierte dritte Tafel. Dagegen sprachen sich u. a. Münzer, S. 36; Schönbauer, S. 169; Griffin (1982), S. 408 und Perl, S. 127 aus, die annahmen, der Antrag habe am Anfang der ersten Kolumne gestanden, was in der römischen Kaiserzeit bei Senatsbeschlüssen durchaus so üblich gewesen wäre.

${ }^{18}$ Vgl. Mommsen, S. 490; Fabia (1929), S. 6-9; Schönbauer, S. 164-169 und zuletzt Chastagnol, S. 7984 , 90. Allerdings nahm etwa Schönbauer an, dass dieses unvollständige Bürgerrecht, dem das Recht zur Belegung von politischen Ämtern in Rom gefehlt habe, nur für peregrine Gemeinden gegolten habe, während Einwohner von römischen coloniae und auch municipia schon seit Augustus das volle Bürgerrecht genossen hätten.

${ }^{19}$ Als erstes machte sich Pelham für diese Alternative stark, da er keine Quellenbelege für ein defizitäres Bürgerrecht für Provinziale finden konnte. Außerdem sei ein vollständiges Bürgerrecht noch kein hinreichendes Kriterium für die Aufnahme in den Senat gewesen. Letztere habe sich durch Absolvieren der Ämterlaufbahn oder durch direkte Adlektion vollzogen. Dabei favorisierte Pelham, S. 441f., die adlectio, da dies eine Maßnahme sei, die Claudius nur in seiner Rolle als Censor von 47 bis $48 \mathrm{n}$. Chr. wahrnehmen konnte, und deswegen die Bitte der Gallier in diese Zeit fiele. Zu den Aufnahmemodalitäten in den Senat vgl. Talbert, S. 39-112; Schäfer, S. 16-24; Syme, S. 12-17).

Für die Verleihung des breiten Purpurstreifen sprachen sich in der Folge Last, S. 59; Vittinghoff, S. 302; Syme, S. 94; Riess, S. 240-243; Levick, S. 101, aus. Für die von Pelham favorisierte Version der direkten Adlektion votierte auch Schillinger-Häfele (1965), S. 443f. Hardy (1913), S. 84, ergänzte noch das Argument, dass sich die Gallier aus überwiegend peregrinen civitates nicht durch Meriten in der Verwaltung ihrer Heimatstädte für ein Amt in Rom empfehlen konnten, sodass der normale Weg über den latus clavus, das Vigintivirat und die Wahl zur Quästur für sie nur sehr schwer anzutreten sei. Cunningham (1915), S. 60, bezweifelte diese These und machte eher die dignitas, also das Ehrgefühl, der vermutlich schon etwas betagteren, sicherlich aber sehr einflussreichen gallischen Adligen für die Ablehnung eines langsamen Aufstieges in der Senatshierarchie verantwortlich. Die Adlektion bot ihnen dagegen die Möglichkeit, gleich im Rang eines ehemaligen Quästors (adlectio inter quaestorios) oder gar als gewesener Volkstribun (a. inter tribunicios) in den Senat einzutreten, ohne diese Ämter auch wirklich ausgeübt zu haben. Schäfer, S. 21f., sprach sich für eine Unterscheidung zwischen ius adipiscendorum in urbe honorum und dem senatorum in urbe ius aus, das die Häduer erhielten. Demnach sei die Möglichkeit, den latus clavus zu erhalten, sämtlichen gallischen Großen gewährt worden, während die Häduer besonders privilegiert wurden, indem man einige von ihnen durch die direkte adlectio aufnahm. Eine unentschiedene Position nahmen Flach, S. 314f., der es für wahrscheinlich hielt, der Text des senatus consultum hätte die Entscheidung darüber dem Kaiser überlassen, und Perl, S. 115f., Anm. 2, ein. Der letzte ergänzte allerdings, dass der latus clavus allein nicht die Aufnahme in den Senat bedeutete, und stellte deswegen die Alternative der Adlektion oder der Verleihung des latus clavus und eines Einstiegsamtes für den Senat zur Diskussion. 
Chance darauf hatten, dadurch dass sie in die Netzwerke der Senatsaristokratie eingebunden waren, bei der Besetzung eines frei werdenden Senatorensitzes berücksichtigt zu werden, wurden die nordgallischen Ritter aus der Gallia Comata bisher nicht in Erwägung gezogen, obwohl es dafür keine rechtlichen Schranken mehr gab.

Genauso wenig wie die Alternative latus clavus oder Adlektion wurde bisher geklärt, inwieweit Claudius den Wünschen der Gallier nachkam. Jedenfalls scheinen 48 und in den unmittelbar darauf folgenden Jahren nur wenige Gallier in den Senat aufgenommen worden zu sein. ${ }^{20}$ Deswegen wurde der Stellenwert der Maßnahme bezüglich der Gallier im Jahr 48 bisher eher als ein Präzedenzfall für spätere Ergänzungen des Senats durch Provinziale charakterisiert, wobei seine kurzfristigen Auswirkungen auf die Zusammensetzung des Senats marginalisiert wurden. ${ }^{21}$ Insgesamt gingen bei der Bewertung der Folgen der Maßnahme freilich auch hier die Meinungen stark auseinander. ${ }^{22}$

Obwohl die Einschätzung, die Rede habe einen Präzedenzfall für die allmähliche Öffnung des Senats für provinziale, stark romanisierte Eliten geschaffen, häufig vertreten wurde, ist bisher kaum in den Blick geraten, inwiefern die Argumentation der Rede denn überhaupt auch auf andere provinziale Eliten als die primores Galliae aus der Gallia Comata anwendbar ist. ${ }^{23}$ Deswegen versucht diese Untersuchung, nun genau hier Klarheit zu schaffen.

\section{II}

Um den historischen Kontext der Rede des Claudius rekonstruieren zu können, sind wir trotz der oben dargestellten Kritik an seiner Darstellungsweise auf Tacitus als Quelle angewiesen. Allerdings erscheinen viele seiner Angaben schlüssig und zu den Hinweisen, die das Original gibt, passend. Kritische Punkte werden im Nachfolgenden noch behandelt werden.

Tacitus verortete die Rede des Claudius während dessen Censur im Jahr 48 n. Chr., was man an den vorangestellten Namen der consules ordinarii für dieses Jahr feststellen kann. ${ }^{24}$ Des Weiteren wurde Claudius in den Annalen kurz nach der Rede von Tacitus als Censor bezeichnet. ${ }^{25}$ Die Datierung des Tacitus kann man durch die

\footnotetext{
${ }^{20}$ Pelham, S. 443, Dessau, S. 160f., Levick, S. 101, und Riess, S. 246f., vermuteten lediglich eine kleine Anzahl der bei Tacitus genannten Häduer. Laut Riess, S. 230, Anm. 1, gelangte wohl auch mittelfristig keine größere Zahl von Galliern in den Senat. Es lässt sich bisher nur der Vater des Iulius Vindex aus aquitanischem Königsgeschlecht als potentiell um 48 in den Senat gelangter Gallier nachweisen. Iulius Vindex trat als Statthalter von Gallia Lugdunensis 68 n. Chr. als Anführer eines Aufstandes gegen Nero in Erscheinung. Sein Vater gehörte wegen seiner aquitanischen Herkunft aber nicht zum Stamm der schon angesprochenen Häduer (Cass. Dio LXIII 23, 1-6). Neben diesen müssen also auch vereinzelt Angehörige anderer Stämme in den Senat gelangt sein.

${ }^{21}$ Vgl. Pelham, S. 443; Vittinghoff, S. 302-304; Riess, S. 247.

${ }^{22}$ Vgl. etwa Griffin (1982), S. 413f., 417. Sie ging von einer Ausnahmeregelung für die Gallier aus, die aufgrund von Claudius' Geburt im gallischen Lugudunum auf persönliche Sympathien hätten bauen können. Demnach wäre es den Galliern als einzigen Provinzialen von Claudius erlaubt worden, in den Senat zu gelangen. Die Rekrutierung der Senatoren aus Italien sei sonst die Regel gewesen.

${ }^{23}$ Griffin (1982) kritisierte, dass dies von Tacitus zwar mit seiner Neufassung der Rede gerade versucht worden wäre (vgl. S. 418), dabei aber der Spezialfall Gallien in den Hintergrund geraten sei (vgl. S. 411). Dass es Tacitus gelungen war, diesen Eindruck zu schaffen, zeigte die Untersuchung von Flaig. Dies untermauert erneut, warum sich diese Untersuchung in Bezug auf die Argumentation der Rede ausschließlich auf das epigraphische Original stützen kann und nicht auf die taciteische Fassung.

${ }^{24}$, A. Vitellio L. Vips $<t>$ ano consulibus“ (Tac. ann. XI 23, 1).

${ }^{25} \mathrm{Vgl}$. Tac. ann. XI 25, 2.
} 
Originalrede verifizieren, in der Claudius von seiner Censur sprach. ${ }^{26}$ Eine genauere Datierung innerhalb des Jahres 48 wurde zwar versucht ${ }^{27}$ ist aber von der Forschung sehr skeptisch beurteilt ${ }^{28}$ oder danach gar nicht mehr rezipiert worden.

Aus der Darstellung des Tacitus geht nur noch hervor, dass die Rede als Reaktion auf eine Diskussion gehalten wurde, die aufkam, nachdem eine Anzahl führender Persönlichkeiten aus Gallien eine Abordnung mit der Bitte um das ,ius adipiscendorum in urbe honorum “29 entsandt hatte. Da unter diesen primores Galliae die Vertreter der 60 Stammesgemeinden zu verstehen sind und diese sich alljährlich am 1. August als concilium Galliarum trafen, ist eine Datierung nach dem 1. August 48 auf jeden Fall gesichert. Die Initiative ging nach Tacitus von den Galliern aus, die wohl von der Censur des Claudius gehört hatten und sich diese Gelegenheit, bei der viele neue Senatoren in den Senat gelangen konnten, nicht entgehen lassen wollten. ${ }^{30}$

Die Bitte der Gallier löste in Rom offenbar einen ,multus [...] variusque rumor" aus, der auch ,apud principem ${ }^{\text {“31 }}$ für heftige Diskussionen sorgte. Mit dem letzten Zitat scheint Tacitus auf den kaiserlichen Rat hinzudeuten, einem Gremium, in dem zur Zeit des Claudius führende Senatoren und vielleicht die Freigelassenen saßen, die den kaiserlichen Behörden vorstanden. ${ }^{32}$

Tacitus nannte zunächst die Argumente der Gegner des gallischen Antrags, ohne deren Identität oder regionale Herkunft preiszugeben. Allerdings waren die Gegner wohl schon mit der bereits erfolgten Ergänzung des Senats durch Senatoren aus der norditalischen Transpadana nicht einverstanden. Das lässt vermuten, dass sich hier wohl vor allem die Angehörigen der alten Senatsaristokratie aus der Stadt Rom und aus Mittelitalien zu Wort meldeten. ${ }^{33}$

Wie Tacitus weiter berichtete, wendete sich Claudius nun gegen diese Opposition, indem er den Senat einberief und seine Rede für die Sache der Gallier hielt. Darauf sei sofort der Senatsbeschluss gefolgt, mit dem der Antrag des Kaisers angenommen wurde. ${ }^{34}$

Tacitus stellte Claudius als vehementen Verfechter der Zulassung gallischer Senatoren dar, wobei auch indirekt einige seiner Intentionen offengelegt wurden.

\footnotetext{
${ }^{26}$ Vgl. Oratio Claudii Caesaris Col. II, Z. 6. Die Censur der Jahre 47/48, wie auch der Kaisertabelle von Kienast, Eck und Heil (S. 82) zu entnehmen ist, hatte neben dem Antrag der Gallier noch viele andere Maßnahmen zur Folge. Claudius hatte nach Meinung der Forschung sicherlich von Anfang an einige Umbesetzungen im Senat im Auge gehabt, allerdings wohl nichts mit dem Antrag der Gallier zu tun. Vgl. dazu Griffin, S. 413f., Riess, S. 246. Nach Suet. Claud. XXIX 2, seien die personellen Ergänzungen eher durch die in den ersten Regierungsjahren des Claudius erfolgten Reinigungen des Senats notwendig geworden, bei denen wohl eine größere Anzahl Senatoren zu Tode kam.

${ }^{27}$ Vgl. Carcopino, S. 179. Dieser datierte die Rede auf Mitte August.

${ }^{28}$ Vgl. Fabia (1931), S. 118-131.

${ }^{29}$ Tac. ann. XI 23, 1.

${ }^{30}$ Vgl. Vittinghoff, S. 299.

${ }^{31}$ Tac. ann. XI 23, 1-2. Es gab also einen ,ausführlichen und kontroversen Disput“, der zu Diskussionen ,in Anwesenheit des Princeps“ führte.

${ }^{32}$ Vgl. Dessau, S. 159; Münzer, S. 35; Griffin (1982), S. 413f. Im Rat wurden offenbar u. a. die Anträge, die dem Senat vorgelegt werden sollten, vorab besprochen. Griffin nahm an, dass damit auch weitgehend die Senatsdebatte abgeschafft wurde, der Senat also die Beschlüsse des Rates nur noch abnickte. ${ }^{33} \mathrm{Vgl}$. Tac. ann. XI 23, 3. Außerdem spricht für ihre mittelitalische Herkunft, dass sie das Bild des verarmten aber ehrbaren Senators aus Latium bemühten, der durch die Konkurrenz reicher Fremder in noch größere Schwierigkeiten gerate.

${ }^{34} \mathrm{Vgl}$. Tac. ann. XI, 25, 1.
} 
Zum einen sah Tacitus bei Claudius durchaus finanzielle Interessen, ${ }^{35}$ zum anderen aber auch die Einsicht der Notwendigkeit von Reformen, um das Imperium Romanum dauerhaft stabil und stark zu halten. ${ }^{36}$ Gerade diese Deutungen des Tacitus, die von einigen Forschern stark in Zweifel gezogen wurden, sollten aber sorgfältig auf ihre Authentizität überprüft werden.

So warf etwa K. Wellesley ${ }^{37}$ Tacitus vor, bewusst die Äußerung der Gegner dieser Neuerung in eine vorhergehende Debatte ins kaiserliche consilium verlegt zu haben, obwohl die Argumente tatsächlich im Senat vorgetragen worden seien. F. Münzer behauptete sogar, der Antrag des Kaisers sei in dieser Debatte noch verworfen und durch einen deutlich restriktiveren Antrag eines Senators ersetzt worden, der die für alle gallischen Stämme geplanten Vergünstigungen zunächst nur den Häduern zugestand. ${ }^{38}$

Außerdem wurde Tacitus unterstellt, er habe in seinen Bemühungen, die Opposition rückwärtsgewandter und polemischer darzustellen, als sie in der Realität auftrat, auch ihre soziale Trägerschaft verändert ${ }^{39}$ und damit die Fronten dieses Konflikts verschleiert.

Eine vollständige Klärung dieses Sachverhalts kann sicher nicht gelingen, da keine eindeutigen Hinweise auf die regionale Herkunft der opponierenden Senatoren oder deren Argumente sowie die Intentionen des Claudius vorhanden sind. Immerhin scheint die rhetorische Frage in Col. II, Z. 5 darauf hinzudeuten, dass die Konfliktlinien eher zwischen Italikern und Provinzialen verliefen. Über die Intention des Claudius wird die folgende Untersuchung noch Aufschluss geben. In erster Linie soll es aber darum gehen zu prüfen, inwieweit Claudius eine über den konkreten Fall der Gallier hinausgehende Legitimationstheorie bemühte, um sein Ziel, einen Senatsbeschluss über die Aufnahme einiger Gallier in den Senat, zu erreichen.

Festzuhalten bleibt bisher, dass man in diesem konkreten Fall von keiner planmäBigen „Provinzialisierung“ des Senats durch eine wie auch immer geartete kaiserliche Integrationspolitik gegenüber den provinzialen Eliten sprechen kann. Dafür waren die Auswirkungen dieser Reform, die nur bei Tacitus überhaupt erwähnt wurde, zu gering. Auch ging die Initiative von den Galliern aus, deren Antrag Claudius wohl eher nicht vorausgesehen, aber gleichwohl unterstützt hatte. Immerhin kann diese gallische Initiative durchaus als mittelbare Folge kaiserlicher Provinzialpolitik gesehen werden, da das Gremium, das die Gesandtschaft schickte, erst von Augustus ins Leben gerufen worden war.

\footnotetext{
${ }^{35}$ Vgl. ebd. XI 24, 6.

${ }^{36}$ Das zeigte seine gesamte Argumentation, in der er wichtige politische Reformen mit innenpolitischer quies (ebd. XI 24, 3) in Verbindung setzt oder dem weisen Handeln des Romulus, der seine ehemaligen Feinde zu Bürgern machte, den Untergang der Machtstellung von Athen und Sparta wegen ihrer mangelnden Integrationsbereitschaft gegenüber den von ihnen unterworfenen Völkern gegenüberstellt (vgl. ebd. XI 24,4).

${ }^{37}$ Vgl. Wellesley, S. 25.

${ }^{38}$ Vgl. Münzer, S. 37f. Dieser Darstellung widersprach aber zuletzt Riess, S. 218, der anführte, dass es sich der kaiserzeitliche Senat weder leisten konnte, so offen in Opposition zu einem Princeps zu treten, noch Claudius die Wünsche der Gallier als ihr Patron missachten durfte (vgl. ebd., S. 240).

${ }^{39}$ Vittinghoff, S. 306 führte etwa an, dass bei Claudius eher der Gegensatz Italiker-Provinziale und nicht der einer mittelitalischen Senatsaristokratie aus republikanischer Zeit gegenüber sowohl norditalischen als auch provinzialen Neu-Senatoren wie bei Tacitus deutlich würde. Tacitus hätte diesen Gegensatz bewusst verschoben, um den Kreis der oppositionellen Senatoren als noch restriktiver und konservativer darzustellen, da er nicht nur gegen die Senatoren aus den Provinzen, sondern auch gegen Senatoren aus Norditalien sei. Griffin (1982), S. 406f. stimmte ihm darin zu.
} 
Obwohl das rhetorische Geschick und die Argumentationsweise des Claudius in der Originalrede lange Zeit wenig Anklang in der Forschung gefunden haben, ${ }^{40}$ offenbart sich bei genauerer Analyse doch eine deutliche Argumentationsstruktur. Diese ist allerdings vor allem durch die Lücke zwischen der ersten und der zweiten Kolumne nicht vollständig, aber doch in großen Teilen erhalten. Schon jetzt sollte angemerkt werden, dass Claudius den Gang seiner Argumentation zumindest zu Anfang (Col. I, Z. 8 - Col. II, Z. 8) nach chronologischen Gesichtspunkten gliederte und deswegen hin und wieder, bevor er schon sämtliche Belege für ein Argument gebracht hatte, zu einem anderen Argument überging.

$\mathrm{Zu}$ Beginn des erhaltenen Teils der Inschrift ${ }^{41}$ wollte Claudius einen Einwand der Gegner, den er vorhersah, abwehren. Es handelte sich dabei um den oft vorgebrachten Vorwurf, Claudius habe eine Neuerung im Sinn, die, wie Claudius vermutete, in der senatorischen Oberschicht gleich auf Ablehnung stoßen musste. ${ }^{42}$ Dagegen ermahnte er seine Zuhörer zu bedenken, dass die Verfassungsgeschichte des römischen Staates bereits auf viele Neuerungen zurückblicke.

Diese These versuchte er zunächst durch viele Beispiele aus der Königszeit zu belegen. Die Länge und der Detailreichtum dieses immerhin zwanzig Zeilen umfassenden Abschnitts fanden in der Forschung wenig Lob. Oft wurden die aufgeführten Beispiele als unnötig für die Argumentation und nur der Selbstdarstellung des Historiker-Kaisers Claudius dienend dargestellt. ${ }^{43}$ Dieses Verdikt ist aber bei genauerer Betrachtung der gewählten Exempla nicht mehr aufrecht zu erhalten.

Zuerst ging Claudius darauf ein, dass die meisten der Könige, die über Rom geherrscht hatten, entweder ,alieni“ oder sogar „externi“44 waren. Während etwa Numa, der zweite römische König, ein Sabiner und damit ein Angehöriger eines benachbarten Volksstamms gewesen sei, habe mit Tarquinius Priscus, dem der Sage nach fünften König von Rom, ein Halbgrieche die Königswürde erlangt. Damit war seine Abstammung ,temeratum. ${ }^{45}$ Außerdem legte Claudius dar, dass die Mutter des Priscus als Tarquinierin ,generosa sed inopi“46 ${ }^{“ 4}$ gewesen sei und Priscus selbst wegen seiner Herkunft in seiner Heimatstadt Tarquinii keine Ehrenämter übernehmen konnte. Damit hatte Tarquinius Priscus also gleich drei wichtige Voraussetzungen nicht erfüllt, die einen nach dem Verständnis der Zeitgenossen des Claudius für hohe honores in Rom qualifizierten: Er war nicht von vornehmer Herkunft, seine Vorfahren waren

\footnotetext{
${ }^{40}$ Besonders stark war dies in der älteren Forschung etwa bei Münzer, S. 43; Hardy (1913), S. 82; Dessau, S. 159f.; Staehelin, S. 167-169, der Fall, aber ebenfalls - wenn auch differenzierter - bei Griffin (1990), S. 482, 485, 491; Syme, S. 98f. und Riess, S. 218.

${ }^{41}$ Vgl. Col. I, Z. 1-7.

${ }^{42}$ Vgl. ebd., Z. 2-4.

${ }^{43}$ Vgl. u. a. Hardy (1913), S. 82, und die übrige Literatur aus Anm. 12.

${ }^{44}$ Col. I, Z. 9f. Mit den ersten waren Fremde, also Leute, die nicht der gerade regierenden Königsfamilie angehörten, mit den zweiten Ausländer, also Angehörige anderer Völkerschaften, gemeint. Vgl. Perl, S. 121.

${ }^{45}$ Col. I, Z. 12. Tarquinius Priscus war also wegen des Herkommens seines Vaters Demaratus aus der griechischen Polis Korinth nur mütterlicherseits Tarquinier und damit seine Herkunft nach Übersetzung von Perl, S. 122, „unebenbürtig“ oder mit den Worten Walsers ,,angefochten“. Die Nennung von Numa, einem Sabiner aus Mittelitalien, der also nach den Maßstäben der claudischen Epoche einen Angehörigen eines uralten Patriziergeschlechts darstellen würde, verdeutlichte am meisten, wie stark sich die Wahrnehmung von Ausländern und Landsleuten mit der Zeit verändert hatte - ein Vorbild für die Entwicklung, die sich Claudius vielleicht auch in Bezug auf die provinzialen Senatoren erhoffte.

46 „vornehm aber mittellos“ (Col. I, Z.13).
} 
teilweise verarmt gewesen, und er hatte noch keine Ehrenämter in seiner Heimat ausgeübt, war dort sogar von der politischen Teilhabe ausgeschlossen gewesen. Größer könnte der Kontrast zu den primores Galliae nicht sein, die zumindest nach Tacitus reich und in der Heimat schon in hohen Ämtern waren. Wenn sich diese aber so positiv von dem einstigen König abhoben, dann konnte ihnen doch schlecht der Zugang zum Senat verwehrt werden. ${ }^{47}$

Den letzten fremdstämmigen König, den Claudius anführte, behandelte er besonders ausführlich, obwohl dieser anders als der zuvor genannte Tarquinius Priscus nicht ganz in seine Argumentation zu passen scheint. Allerdings bot das betreffende Beispiel des Etruskers Servius Tullius Claudius die Möglichkeit, mit seinen Kenntnissen in der etruskischen Geschichte zu glänzen, über die er selbst ein Geschichtswerk veröffentlicht hatte. ${ }^{48}$ Neben dieser in der Forschung häufig vorkommenden These sollte aber nicht übersehen werden, dass es sich bei Servius Tullius offenbar um einen sehr verdienten König handelte, da Claudius dessen Regierungszeit als „summa cum rei p(ublicae) utilitate“499 bezeichnete. Außerdem war Servius Tullius als etruskischer Feldherr ebenfalls kein Römer und hatte seinen römischen Namen erst nach seiner Übersiedelung dorthin angenommen. Das war ein Vorgang, der mit der Annahme eines römischen Bürgernamens korrespondierte, den Provinziale sich mit Erhalt ihres Bürgerrechts zulegten. Durch die Ausführlichkeit, mit der sich Claudius diesem König widmete, hoffte er vielleicht auch, die Reizthemen seiner Rede zunächst noch zu vermeiden und stattdessen das Publikum durch seine gelehrten Exkurse für sich einzunehmen. ${ }^{50}$

Nach seinem Gang durch die Chronologie der römischen Könige führte Claudius seine Argumentation durch die Aufzählung verschiedener Verfassungsänderungen in der frühen und mittleren Republik fort. Auch über die Funktion dieses Abschnitts der Kaiserrede (Col. I, Z. 28-37) wurde lange Zeit gerätselt. ${ }^{51}$ Zwar schien

\footnotetext{
${ }^{47}$ Eine ähnliche Beurteilung findet sich bei Wellesley, S. 20. Auch für Perl, S. 122, war das Beispiel passend gewählt.

${ }^{48} \mathrm{Zu}$ Claudius' Tätigkeit als Historiograph vgl. Malitz. Dieser Umstand wurde in der Forschung bisher fast ausschließlich bemüht, um die Ausschweifungen des Claudius bei diesem Exemplum zu erklären und prägte auch das Urteil über den Inhalt der ersten Kolumne stark. Vgl. dazu Hardy (1913), S. 82; Staehelin, S. 167; Miller, S. 308; Perl, S. 123; Albrecht, S. 116.

49 „Zum höchstem Nutzen für das Gemeinwesen“ (Col. I, Z. 23f.).

${ }^{50}$ So argumentierte etwa Albrecht, S. 132, der in seiner Stilanalyse der ersten Kolumne der Rede auf die Verbindung der eloquenten Ausdrucksweise eines Historikers und eines an Mündlichkeit grenzenden, lockeren Stils' verwies. Vgl. ebd., S. 121f.

${ }^{51}$ Laut Albrecht, S. 116, passte nicht alles zur eigentlichen Argumentation. Vittinghoff, S. 307, merkte an, dass die Beispiele bewusst der Zeit vor Ausbruch der Bürgerkriege in der späten Republik entnommen seien, um damit die Opposition aus mittelitalischen Senatoren anzusprechen, wie sie Tacitus darstelle. Diese sähe natürlich gerade in der Zeit der frühen und mittleren Republik ihr ,goldenes Zeitalter“. Dadurch, dass nun aufgezeigt würde, dass gerade diese Zeit von vielen Neuerungen in der Politik geprägt worden war, sollte nun die innovationsfeindliche Haltung dieser Opposition gebrochen werden. Vittinghoff verkannte hier, dass die Gegner der anstehenden Neuerung, wie später in der Rede noch deutlich wurde, vermutlich erst nachträglich von Tacitus zu jenen ultrakonservativen Senatoren aus Mittelitalien erklärt wurden, um ihre Position schwächer erscheinen zu lassen. In der Realität war die soziale Trägerschaft der Opposition wohl sehr viel größer, da die Aufnahme von Galliern aus den drei nördlichen gallischen Provinzen auch für Senatoren aus Norditalien oder gar den stark romanisierten und städtisch geprägten Provinzen wie der Baetica auf der iberischen Halbinsel oder aus der Gallia Narbonensis ein Affront bedeuten konnte. Schließlich konnten die gallischen primores wegen der noch überwiegend tribalen Gesellschaft in ihrer Heimat mit nur wenigen städtischen civitates keine städtischen Ämter übernommen haben, bevor sie Senatoren wurden, verfügten aber über eine größere Gefolgschaft als ihre Senatskollegen aus den stärker romanisierten Provinzen.
} 
klar zu sein, dass Claudius hier sein großes Vorbild, den Historiker Livius, stilistisch nachahmte, da die Aufzählung der einzelnen Veränderungen zum Teil stark an die des Volkstribunen C. Canuleius bei Livius erinnerte. ${ }^{52}$ Aber damit wurde noch nicht geklärt, welche Funktionen die aufgezählten Verfassungsänderungen in Bezug auf das eigentlich behandelte Problem, die Zulassung von Galliern zum Senat und zu den römischen honores, einnahmen. Letztendlich scheint am ehesten noch das letzte Beispiel zum eigentlichen Thema zu passen, da es hier um die Zulassung von Plebejern, einer zuvor politisch nicht integrierten Schicht der stadtrömischen Bevölkerung, zu den Magistraten und Priesterämtern ging. ${ }^{53}$ Die restlichen Beispiele repräsentierten zwar ebenfalls Neuerungen, hatten aber nichts mit einer politischen Integration von bisher nicht an der Herrschaft beteiligten Bevölkerungsteilen zu tun.

Tatsächlich sind diese Beispiele eher in dem Sinne zu verstehen, dass hier auf Neuerungen verwiesen werden sollte, die allgemein beträchtliche Auswirkungen auf die römische Geschichte entfaltet und zur zeitweiligen Stabilisierung der res publica beigetragen hatten. Beispielsweise bewirkte das Ende der Ständekämpfe, das unter anderem durch die Einführung des Volkstribunats erreicht worden war, eine innenpolitische Beruhigung, die eine römische Expansion in größerem Ausmaß erst ermöglichte. Dagegen dokumentierten die häufigen Wechsel zwischen Konsulat, Decemvirat, Rückkehr zum Konsulat und schließlich Militärtribunat eine starke Flexibilität der römischen Oberschicht in der Gestaltung ihres Staatswesens. Diese Flexibilität war sehr viel größer gewesen als diejenige, die Claudius von den Senatoren im Jahr 48 n. Chr. verlangte, da die Veränderungen damals die Spitze des Staatswesens betroffen hatten, während es sich bei der claudischen Neuerung nur um die Gewährung eines Privilegs für eine übersichtliche Gruppe von gallischen Adligen handelte, für die Claudius eigentlich der Zustimmung des Senates gar nicht bedurfte. ${ }^{54}$ Zusammenfassend wurden durch diese Beispiele aus der Verfassungsgeschichte also einerseits die hohe Flexibilität der maiores und anderseits die positiven Auswirkungen von einmal etablierten Neuerungen ausgedrückt. Sie dienten der endgültigen Widerlegung des Vorurteils, Neuerungen wären schlecht, weil dadurch der mos maiorum missachtet würde.

Danach verwies Claudius überdies noch auf die militärische Expansion, die das Reich „ultra oceanum“55 - über den Ozean hinaus - erweitert hätte. Damit erinnerte er in erster Linie an die kurz vorher erfolgte Eroberung Britanniens, an der er selbst als Feldherr beteiligt gewesen war. Darüber hinaus zeigten aber natürlich die großen Eroberungen des Imperiums in ihrer Gesamtheit ebenfalls den Erfolg von Veränderungen und hatten immer wieder eine hohe Flexibilität der römischen Nobilität erfordert. Die eher allgemeine Zielsetzung dieses Teils der Argumentation nahm Claudius durchaus als Entfernung vom eigentlichen Thema seiner Rede wahr.

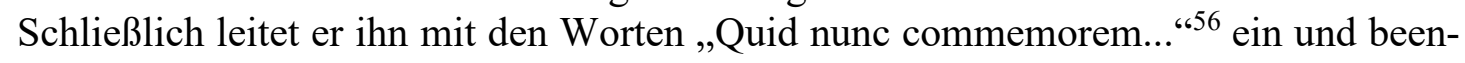
dete nach einer kurzen Bemerkung über die römische Expansion diese Abschweifung mit den Worten „Sed illoc potius revertar“. 57

\footnotetext{
${ }^{52}$ Vgl. Liv. 4, 3-5. Dazu auch: Griffin (1982), S. 408; Perl, S. 126.

${ }^{53}$ Vgl. Col. I, Z. 36f.

${ }^{54}$ Vgl. u.a. Pelham, S. 442f.; Osgood, S. 165.

${ }^{55}$ Col. I, Z. 40.

${ }^{56}$ „Was soll ich jetzt noch erwähnen, ...“ (ebd., Z. 28).

57 „Lieber will ich zu diesem Punkt zurückkehren.“ (ebd., Z. 40).
} 
Nach diesem Exkurs über die römische Verfassungsgeschichte und Expansion findet sich vor der mittleren Lücke der Inschrift nur noch das Wort „civitatem““. ${ }^{58}$ Mit diesem einen Wort versuchten einige Forscher, den ungefähren Inhalt des fehlenden Mittelteils der Rede zu rekonstruieren. Nach verbreiteter Lesart sei es Claudius in dem fehlenden Abschnitt um das Bürgerrecht gegangen, in dessen Genuss ein stetig erweiterter Kreis von Einwohnern des Imperiums im Gefolge der militärischen Expansion gekommen sei. ${ }^{59}$ Allerdings ging Claudius zuvor auf die militärischen Erfolge Roms und die Ausdehnung des Imperiums bis nach Britannien eben nur im Rahmen eines kurzen Seitenblicks ein und kehrte dann zum Punkt „Bürgerschaft“ zurück. Damit verband er die Verbreitung des Bürgerrechtes, sofern sie überhaupt im nachfolgenden Abschnitt thematisiert wurde, nicht mit der militärischen Expansion, sondern wahrscheinlich mit den vorausgegangenen Ausführungen über die fremden Könige. Er nahm damit also gleich die mögliche Folge der Verleihung des Bürgerrechts, nämlich die Partizipation der Neubürger an der Herrschaft, in den Blick.

Diese Überlegungen lassen den Umfang der mittleren Lücke noch sehr viel kleiner erscheinen, da es gleich im nächsten erhaltenen Satz um das politische Prinzip von Augustus und Tiberius, den beiden ersten Principes, ging, das laut Claudius darin bestanden hätte, die „omnem florem ubique coloniarum ac municipiorum “60 im Senat vertreten haben zu wollen. Diese Textstelle führte in der Forschung zu einer kontroversen Diskussion über ihre genaue geographische Dimension, die bis heute nicht endgültig geklärt zu sein scheint. Dabei vertrat die eine Seite die Meinung dieses ubique in Verbindung mit coloniarum ac municipiorum hätte sich nur auf die Landstädte Italiens bezogen. Augustus und Tiberius hätten also lediglich Senatoren aus allen Gegenden Italiens im Senat haben wollen, während vorher gewisse Regionen der Halbinsel noch keinen Senator gestellt hatten. ${ }^{61}$

Dieser Sichtweise widersprachen andere Althistoriker, die dabei einerseits mit dem nachfolgenden Text der Rede und andererseits mit den historischen Fakten argumentierten. Für sie bezog sich das ubique auf das gesamte Imperium Romanum, also auch auf Städte in den Provinzen, sofern sie den Status einer colonia oder eines municipium besaßen. Obwohl insgesamt aufgrund der belegten provinzialen Senatoren in der augusteischen Zeit die Erklärung dieser zweiten Gruppe von Forschern

\footnotetext{
${ }^{58} \mathrm{Ebd}$.

${ }^{59}$ Vgl. u.a. Wellesley, S. 17; Vittinghoff, S. 307; Perl, S. 127. Belegt wurde dies eher nicht durch den Text der Originalrede, sondern mit dem Verweis auf das entsprechende Vorgehen bei Tacitus, militärische Expansion mit der Verbreitung des Bürgerrechts zu verschränken (vgl. Tac. ann. XI 24, 3). Genau vor diesem Vorgehen warnte allerdings Wellesley, S. 19, der den fehlenden Inhalt aus der Originalrede alleine rekonstruiert haben wollte.

60 „die gesamte Blüte aus den Kolonien und Munizipien von überall her“ (Col II. Z. 3). Dabei meinte „omnem florem“, wie Claudius später ausführte, die besten und wohlhabendsten Männer dieser Städte (vgl. ebd. Z. 3f.). Zu den Begriffen colonia und municipium siehe Galsterer (1997) und ders. (2000).

${ }^{61}$ Dabei stützte man sich in erster Linie auf die These, dass auch zur Zeit von Claudius coloniae ac municipia als Synonym für Italien gebraucht wurde und das ubique in diesem Fall also nur ganz Italien meinte. Die Verfechter dieser Auslegung führten aber auch an, die Rekrutierung von Senatoren aus Italien sei ein von Augustus bewusst gewähltes Prinzip gewesen, um sich damit gegenüber der Bürgerkriegszeit abzuheben, in der mehrere provinziale Senatoren in den Senat gelangt waren. Zum dritten versuchten sie auf teilweise recht abenteuerliche Weise, den Text der Claudiusrede in ihrem Sinne umzuinterpretieren, obwohl doch im folgenden Redeabschnitt provinziale Senatoren aus der Zeit der Vorgänger des Claudius genannt wurden. Vgl. dazu Cunningham (1914), S. 132; Cunningham (1915); Last, S. 59f.; Schillinger-Häfele (1965), S. 446-448; Levick, S. 106; Griffin (1982), S. 408.
} 
plausibler erscheint, kann man die erstgenannte Sichtweise sicherlich nicht endgültig ausschließen. ${ }^{62}$

Unabhängig von dieser Forschungskontroverse wollte Claudius seine Maßnahme hier ganz klar als Fortführung der Politik seiner Vorgänger darstellen, was ihm in dem Fall, dass Augustus und Tiberius nur Senatoren aus allen Gegenden Italiens rekrutiert hätten, sehr viel schwerer gefallen wäre, als wenn diese bereits auch Senatoren aus römischen Kolonien und Munizipien außerhalb Italiens zugelassen hätten. So hätte er den römischen Senatoren sicherlich plausibel erklären können, dass zwischen römischen Rittern aus Städten in den Provinzen, die sich nur in Bezug auf ihr Stadtrecht voneinander unterschieden, nach so langer Zeit unter römischer Herrschaft kein großes Zivilisationsgefälle mehr bestand und sie deshalb in Bezug auf ihre Chancen, in den Senatorenstand aufzusteigen, eine Gleichbehandlung verdienten. Dies wäre ihm bei der Gegenüberstellung von Senatoren aus Italien und Nordgallien vermutlich nicht gelungen und hätte ihn dazu gezwungen, die anwesende römische Nobilität auf nahezu dieselbe Stufe wie die Leute aus dem behaarten Gallien zu stellen.

In beiden Fällen waren aber Augustus und Tiberius laut Claudius dazu übergegangen, die Herkunftsgebiete der Senatoren durch Aufnahme von homines novi aus bisher nicht berücksichtigten Gebieten - in Italien oder auch in den Provinzen - auszuweiten. An dieser Stelle kehrte Claudius also erkennbar zu seinem eigentlichen Thema zurück, dass eine Beteiligung von Fremden an der römischen Herrschaft nichts schlechtes oder ungewöhnliches in Rom wäre, sondern gewissermaßen Tradition hatte.

Der Princeps verband dies jedoch mit einem klaren Bekenntnis zum Vorrang der italischen Senatoren, indem er die rhetorische Frage stellte: „Quid ergo? Non Italicus senator provinciali potior est?" ${ }^{\prime 63}$ Diesen Vorrang wollte er auch in den anderen Maßnahmen seiner Censur deutlich werden lassen, womit er wohl auf die Erhebung einiger italischer Geschlechter in das Patriziat hindeutete, die er laut Tacitus kurz nach der Rede durchführte. ${ }^{64}$

Claudius unterschied also ausdrücklich zwischen Italikern und Provinzialen, womit er wahrscheinlich die Denkkategorien und die Befürchtungen der Gegner seiner Maßnahme aufnahm. Eine solche Position. Dieser Gegensatz war aber eher typisch für Senatoren aus Norditalien, die sich damit auf eine Stufe mit der mittelitalienischen, altrömischen Nobilität stellten, während eine auf Mittelitalien beschränkte Opposition wohl ebenso Front gegen die Senatoren aus der Transpadana gemacht hätte. Deswegen scheinen die Gegner, anders als Tacitus Bericht es nahelegte, nicht nur aus Mittelitalien, sondern aus ganz Italien gekommen zu sein.

\footnotetext{
${ }^{62}$ Die Vertreter dieser Interpretation beriefen sich dabei auf die vielen Zeugnisse von provinzialen Senatoren vor, während und nach der Regierungszeit des Augustus und die nachfolgende Argumentation in der Rede, in der provinziale Senatoren aus der Zeit vor der Regierung des Claudius genannt werden. Außerdem gehe es Claudius in der Rede gerade darum, seine Maßnahme als Fortsetzung der Politik seiner Vorgänger und nicht als Abkehr von den Traditionen darzustellen. Wenn aber Augustus und Tiberius nur Senatoren aus tota Italia zugelassen hätten, dann wäre Claudius in erhebliche Erklärungsnot gekommen. Vgl. dazu etwa Hardy (1913); Hardy (1914), S. 283-286; Vittinghoff, S. 303, Anm. 8, S. 308; Wellesley, S. 17; Staehelin, S. 168; Flach, S. 316; Perl, S. 128; Syme, S. 105-110; Schäfer, S. 21-23; Riess, S. 228-230.

${ }^{63}$ „Wie also? Ist nicht ein Senator aus Italien wichtiger als einer aus der Provinz?“(Col. II, Z. 5). Dabei deutet das non (= nonne) auf ein ,ja“ als Antwort hin. Trotz der Erweiterung des Senats durch Provinziale sollten die Italiker also immer noch eine höhere Würde besitzen. Vgl. Vittinghoff, S. 309; Perl, S. 128.

${ }^{64} \mathrm{Vgl}$. Tac. ann. XI 25, 2.
} 
Da Claudius nun hoffte, seine Gegner für sich eingenommen zu haben, leitete er allmählich zum konkreten Fall der gallischen Adligen über. Er näherte sich den drei Provinzen gewissermaßen geografisch, indem er auf die römische colonia Vienna (heute Vienne) zu sprechen kam. Diese lag nahe der Nordgrenze der damaligen Provinz Gallia Narbonensis, nicht in der Gallia Comata, aber doch in deren Nachbarschaft. Claudius referierte, dass diese Kolonie bereits vor langer Zeit Senatoren hervorgebracht habe, nannte dann aber zunächst kein Beispiel eines solchen Senators, sondern seinen Vertrauten Lucius Iulius Vestinus, einen Ritter aus Vienna, den er seine Vermögensangelegenheiten verwalten ließ. Für dessen Kinder bekundete er sein Vorhaben, diese zunächst bei der Erlangung von Priesterämtern und dann auch ihre weitere politische Karriere zu unterstützen. ${ }^{65}$ Danach verwies er auf den sicherlich bekanntesten Senator aus Vienna, den zweifachen Konsul Decimus Valerius Asiaticus, der allerdings aufgrund einer Intrige der Augusta Messalina von Claudius zum Selbstmord gezwungen worden war. Deswegen stellte Asiaticus sicherlich nicht das beste Beispiel für eine erfolgreiche Karriere eines provinzialen Senators dar. Neben vielen negativen Deutungen dieser Passage als Wutausbruch oder nicht in den Redezusammenhang passende Patronagepolitik des Claudius hat sich immerhin mittlerweile auch eine konstruktivere Interpretation dieses Redeabschnitts in der Forschung entwickelt. Nach dieser Lesart wollte Claudius mit dem Beispiel des zuverlässigen Vestinus und dem in Aussicht gestellten langsamen Aufstieg von dessen Familie in den Senatorenstand seine Besonnenheit bei der Verleihung von Privilegien in Erinnerung rufen, die er auch in Bezug auf den Fall der Gallier nicht abzulegen gedenke. Dies sei schließlich im Falle des von Gaius Caesar (Caligula) geförderten Aufsteigers Asiaticus schon einmal nicht gut gegangen. ${ }^{66}$

Nach dieser nicht leicht zu deutenden Passage fuhr Claudius mit einer eher humorvollen und heiteren Passage fort, die die Situation im Senat entspannen sollte. So rief er sich ironisch zur Ordnung und brachte scherzhaft die Senatoren aus Vienna, die er vor sich hatte und die aus dem Stammesgebiet der Allobroger stammten, mit den Vorfahren des Senators Paullus Fabius Persicus in Verbindung, von denen einer den Siegesnamen „Allobrogicus“ - Allobrogersieger - geführt hatte. Claudius, der es natürlich besser wusste, tat nun aber so, als ob die Vorfahren des Persicus selbst Allobroger gewesen seien. Er führte diesen Scherz noch fort, indem er sich selbst indirekt als Senator aus Lugudunum, dem Hauptort der Gallia Comata bezeichnete, obwohl er zwar dort geboren wurde, seine Familie aber aus Italien stammte. ${ }^{67}$

\footnotetext{
${ }^{65}$ Vgl. Col. II, Z. 9-14.

${ }^{66}$ Während die Forschung, wie bei Perl, S. 129-131, dargestellt, das Beispiel des Vestinus meist noch mit dem Anliegen des Kaisers begründete, seinen Vertrauten hier bei der Karriere seiner Söhne zu unterstützen, ließ man sich über das Asiaticus-Beispiel sehr kritisch aus. Man vermutete an dieser Stelle bei Claudius geradezu einen Wutausbruch. Vgl. dazu Dessau, S. 160, und Staehelin, S. 168. Riess, S. 216f., sah das zwar einerseits ähnlich, wollte aber nicht ausschließen, dass Claudius mit diesem Beispiel vor einer vorschnellen Beförderung von provinzialen Aufsteigern warnen wollte. Dann würde Vestinus hier als Beispiel dafür dienen, wie der Aufstieg zum Senator durch Verdienste in ritterlichen Ämtern und über mehrere Generationen idealerweise vonstatten gehen sollte. Diese Ansicht vertrat auch schon Wellesley, S. 17.

${ }^{67}$ Vgl. Col. II, Z. 20-29. Der Scherz ist allerdings lange Zeit nicht als solcher erkannt worden. Vittinghoff, S. 310, dachte, dass Claudius hier den Senator nannte, der von seinen Vorfahren her die besten Gründe hatte, Allobroger im Senat abzulehnen, diese aber respektierte. Schillinger-Häfele (1989), S. 117, ergänzte, die Unterwerfung der Allobroger, die im Siegesnamen Allobrogicus mitklinge, und die allobrogischen Senatoren würden verdeutlichen, wie aus ehemaligen Feinden Freunde und Teilhaber an der römischen Herrschaft geworden wären. Ebenso wurde Claudius in Bezug auf die Senatoren aus Lugudunum beim Wort genommen. Vgl. dazu Hardy (1913), S. 88; Vittinghoff, 310f.; Syme,
} 
Damit konnte er die Senatoren zwar nicht von der Sache überzeugen, die Scherze, vor allem die selbstironische Bezeichnung des Princeps als Senator aus Lugdunum, lockerten aber die Stimmung sicherlich auf.

Überzeugen wollte er die Senatoren im Folgenden auf eine andere Art und Weise. So richtete er seinen Blick auf die Gallia Comata und stellte den Galliern das Zeugnis aus, seit den Kriegen Caesars stets treu zu Rom gestanden zu haben. Damit verschwieg er verständlicherweise einige Aufstände, deren letzter im Jahr $48 \mathrm{n}$. Chr. erst 27 Jahre zurücklag. Im Gegenteil betonte er die gute Zusammenarbeit der Gallier mit seinem Vater Drusus bei dessen Steuerschätzung in Gallien (ab 12 v. Chr.) und während der nachfolgenden Auseinandersetzungen mit germanischen Stämmen am Rhein (12-9 v. Chr.). ${ }^{68}$

Zum Schluss schlug er von dem Census in Gallien einen Bogen zur derzeitigen Tätigkeit in seiner Censur, in der er ebenfalls das Vermögen der römischen Bürger kontrollieren musste, was wie er sagte, nicht immer ohne Reibereien funktioniere. ${ }^{69}$ Damit war er in der unmittelbaren Gegenwart angelangt und hatte seinen chronologischen Gang durch die römische Geschichte beendet. Gleichzeitig benutzte er das Bindemittel der Censur hier zur Verstärkung der Treue der Gallier, da sie damals bei der Censur von Drusus ruhig geblieben wären, während zur Zeit des Claudius eine Censur unter römischen Bürgern in Italien für viele Schwierigkeiten sorgte.

\section{IV}

Insgesamt hat sich diese Untersuchung sehr viel stärker mit dem ersten (Col I, Z. 1 Col II, Z. 8) als mit dem zweiten Abschnitt der Rede des Claudius beschäftigt und steht damit durchaus im Gegensatz zur sonstigen Forschung. Dies ist dem Umstand der konkreten Fragestellung nach einer allgemeinen Legitimationsstrategie für die Ergänzung des Senats durch provinziale Eliten geschuldet. Argumente, die eine derartige, allgemeine Neuerung rechtfertigen würden, findet man nämlich nur im ersten Teil, da danach auf den Spezialfall der gallischen Antragssteller eingegangen wurde. Dennoch nimmt aber dieser zweite Abschnitt einen Großteil der zweiten Kolumne ein, sodass Claudius der „Comatae Galliae causa“70 eine sehr viel größere Bedeutung beimaß als Tacitus, der eher auf die allgemeine Legitimation Wert legte.

Trotz dieser Einschränkung folgte aber auch Claudius einer Legitimationsstrategie, die nicht nur auf die Gallier, sondern darüber hinaus auf die Erweiterung des Senats durch andere provinziale Senatoren anwendbar war. Zum einen erklärte Claudius, dass Neuerungen allgemein ein ständig wiederkehrendes Muster in der römischen Geschichte waren und gerade die gelegentliche Besetzung von hohen Ämtern

S. 100; Riess, S. 217f. Huß, S. 251-253, legte allerdings überzeugend dar, dass Claudius seinen Humor an dieser Stelle dazu einsetzte, die Situation zu entkrampfen und damit darüber hinwegzutäuschen, dass es keine starken Argumente dafür gab, das Rekrutierungsgebiet für den Senat über die ,vertrauten Provinzen“ hinaus auszuweiten. Dieser Ansicht folgten Griffin (1982), S. 409 und Perl, S. 132-134. Meister, S. 42-46, nahm jüngst Claudius auch gegen den Vorwurf in Schutz, er habe in Sachen Humor einen schlechten Geschmack gehabt. Eine besonders „dramatische“ Erklärung für die Passage der Inschrift hatte Wellesley, S. 21-23, ersonnen, der Claudius ein interaktives Schauspiel mit der Gesandtschaft der gallischen Ständeversammlung aufführen sah.

${ }^{68}$ Vgl. Col. II, Z. 35-38.

${ }^{69}$ Vgl. ebd., Z. 38-41. An dieser Stelle wird allerdings die Übersetzung von Perl, S. 136, verwendet, dem auch Albrecht, S. 114, gefolgt ist. Die bisher verwendete Übersetzung von Walser ist m. E. zu sehr bemüht, eine ähnliche Pointe zu erzeugen, wie Tacitus sie vorgab.

${ }^{70}$ Col. II, Z. $31 \mathrm{f}$. 
mit Ausländern eine gewisse Tradition hatte, wofür die fremden Könige in der Frühzeit Pate standen. ${ }^{71}$ Zum anderen bemühte er sich, die Erfolge der Neuerungen und die hohe Flexibilität der Vorfahren durch die Beispiele aus der frühen und mittleren Republik zu zeigen. ${ }^{72}$ Gerade die von der konservativen römischen Oberschicht häufig zum moralischen Vorbild erhobenen maiores lehrten also mit ihren Taten, dass man Veränderungen zulassen müsse, um Erfolg zu haben.

Verständlicherweise musste Claudius - deutlicher, als dies in der Rede in den Annalen durchscheint, - Vorsicht bei der Einführung dieser Neuerungen walten lassen. So wollte er erstens sein Handeln als einfache Fortsetzung eines Neuerungsprozesses darstellen, den seine Vorgänger Augustus und Tiberius - den übel beleumundeten Gaius lässt er verständlicherweise aus - begonnen hatten, indem sie entweder Senatoren aus sämtlichen Gegenden Italiens oder sogar schon ebenfalls aus coloniae und municipia in den Provinzen zugelassen hatten. ${ }^{73}$ In beiden Fällen sollte der Schritt von Claudius nichts anderes als eine weitere Vergrößerung dieses Rekrutierungsgebiets um die gallischen Nordprovinzen darstellen. Auch nannte er die massiven Verfassungsänderungen in der Republik sicherlich, um die anstehende Veränderung dagegen unbedeutend erscheinen zu lassen. Zweitens wollte er die Dominanz der Italiker im Senat keinesfalls beenden oder schmälern, sondern versicherte, auch diese in seinen Maßnahmen angemessen zu begünstigen. ${ }^{74}$ Dieses Versprechen löste er mit der Erhebung einiger italischer Familien in das Patriziat danach ja auch ein. ${ }^{75}$ Drittens nannte er vielleicht nicht ohne Hintergedanken die Beispiele Lucius Vestinus und Valerius Asiaticus. ${ }^{76}$ Während L. Iulius Vestinus ein würdiger Ritter war und deswegen seine Söhne die Chance zur Erlangung von hohen Senatsämtern bekommen sollten - ein Beispiel für den langsamen und kontrollierbaren Aufstieg einer verdienten Provinzialenfamilie -, zeigte Claudius mit seinen negativen Äußerungen über D. Valerius Asiaticus klar seine Ablehnung eines schnellen Aufstiegs einzelner provinzialer Senatoren durch kaiserliche Patronage.

Insgesamt stand Claudius also in Bezug auf die Zulassung von Provinzialen zum Senat für eine vorsichtige Innovation, eine Innovation mit Augenmaß.

Deswegen kann man Claudius sicherlich nicht ohne Einschränkung einen überzeugten Reformer, sondern eher einen vorsichtig agierenden Pragmatiker nennen. Dies zeigt sich schon alleine daran, dass bis auf den Bericht des Tacitus, der besagt, dass einige Häduer die Möglichkeit erhielten, in den Senat zu gelangen, keinerlei Hinweise für eine Umsetzung der Reform existieren. Bei lediglich zwei bekannten Senatoren aus den gallischen Nordprovinzen, von denen vermutlich nur einer um 48 n. Chr. in den Senat gelangte, kann es sicherlich keine entschiedene Förderung des Eintritts von Galliern in den Senat gegeben haben. Claudius sprach ja selbst davon, dass er die Dominanz der Italiker unbedingt erhalten wollte, und holte sich für die Neuerung, die er im Prinzip auch ohne Konsultation des Senats hätte durchsetzen können, dessen Zustimmung ein. ${ }^{77}$ Außerdem ging die Initiative mit allergrößter

\footnotetext{
${ }^{71}$ Vgl. Col. I, Z. 8-27.

${ }^{72}$ Vgl. ebd., Z. 28-40.

${ }^{73}$ Vgl. Col. II, Z. 1-4.

${ }^{74}$ Vgl. ebd., Z. 5-8.

${ }^{75} \mathrm{Vgl}$. Tac. ann. XI 25, 2.

${ }^{76}$ Vgl. Col. II, Z. 9-19.

${ }^{77}$ Schließlich ist mittlerweile in der Forschung allgemein anerkannt, dass es sich bei der Neuerung nicht um eine Bürgerrechtserweiterung handelte, sondern lediglich um die Gewährung einer Vergünstigung durch den Kaiser, nämlich entweder des latus clavus oder einer adlectio, um in den Senat zu gelangen.
} 
Wahrscheinlichkeit von den Galliern aus, wenn auch im Rahmen eines Gremiums, das zuvor von Augustus geschaffen worden war. Diese Initiative unterstützte Claudius dann - allerdings nicht unbedingt um der Innovation willen, sondern einfach aus pragmatischen Überlegungen. Die primores Galliae waren die führenden Vertreter der gallischen Stämme, die einen potenziellen Unruheherd für Rom darstellen konnten, wie die Aufstände von 21 und 68 n. Chr. gezeigt hatten. Eine Befriedigung der integrativen Bestrebungen dieser machtvollen Stammesführer war alternativlos und konnte vielleicht ein wichtiger Schritt zur Befriedung der gallischen Provinzen sein. Diese erschien gerade wegen der von Claudius erwähnten Eroberung Britanniens als dringend geboten, da Gallien nicht mehr den nördlichen Rand des Imperiums markierte, sondern die direkte Verbindung zwischen der neu eroberten Provinz und Roms mediterranem Zentrum darstellte.

Damit scheint der Fall der primores Galliae zu illustrieren, dass den römischen Kaisern aus realpolitischen Überlegungen zwar an einer gewissen Integration der provinzialen Oberschichten gelegen war, sie aber im Normalfall eher auf kaum abzuschlagende Petitionen reagierten und nicht selbst die Initiative ergriffen. ${ }^{78}$ Für solche Fälle schien es allerdings eine Argumentationsstrategie zu geben, die man zur Legitimation der Maßnahme über die tagespolitische Notwendigkeit hinaus nutzen konnte.

\footnotetext{
${ }^{78}$ Hier scheint sich die These von Millar, S. 266f., zu bestätigen, dass die römischen Kaiser wegen der Größe des Reiches kaum zu eigenen politischen Initiativen in der Lage waren, sondern das Reich eher passiv verwalteten.
} 


\section{Quelleneditionen und Übersetzungen}

Cassius Dio, Römische Geschichte, übers. von O. Veh, 5 Bde., Darmstadt 2007.

Titus Livius, Römische Geschichte, hrsg. und übers. von H. J. Hillen, 11 Bde., München 1987-2000.

Cornelius Tacitus, Annalen, hrsg. und übers. von A. Städele, 3 Bde., Darmstadt 2011.

G. Walser, Römische Inschrift-Kunst. Römische Inschriften für den akademischen Unterricht und als Einführung in die lateinische Epigraphik, Wiesbaden 1988 (darin: Rede des Kaisers Claudius für das Ius honorum der Gallier (48 n. Chr./ CIL XIII 6797), Nr. I.3, S. 18-25).

\section{Literatur}

M. von Albrecht, Meister römischer Prosa. Von Cato bis Apuleius. Interpretationen, 4. Auflage, Darmstadt 2012.

G. Alföldy, Konsulat und Senatorenstand unter den Antoninen. Prosopographische Untersuchungen zur senatorischen Führungsschicht, Bonn 1977 (Antiquitas 1, 27).

J. Bleicken, Der politische Standpunkt Dio's gegenüber der Monarchie. Die Rede des Maecenas Buch 52, S. 14-40, in: Hermes 90 (1962), S. $444-467$ (wiederabgedruckt in: F. Goldmann/M. Merl et al. [Hrsg.], Jochen Bleicken, Gesammelte Schriften II. 2. Römische Geschichte [Fortsetzung]; 3. Wissenschaftsgeschichte, Nachrufe, Allgemeines, Stuttgart 1998, S. 876-900).

J. Carcopino, Points de vue sur l'imerialisme romain, Paris 1934 (Collection SaintGermain-Des-Prés, 12).

A. Chastagnol, Le Sénat romain à l'époque impériale. Recherches sur la composition de l'Assemblée et le statut de ses membres, Paris 1992.

A. J. Christopherson, The provincial assembly of the three Gauls in the Julio-Claudian period, in: Historia 17 (1968), S. 351-366.

H. J. Cunningham, Clavdivs and the Primores Galliae, in: CQ 8 (1914), S. 132-133.

ders., Clavdivs and the Primores Galliae, in: CQ 9 (1915), S. 57-60.

J. Deininger, Die Provinziallandtage der Römischen Kaiserzeit. Von Augustus bis zum Ende des dritten Jahrhunderts n. Chr., München 1965 (Vestigia, 6).

H. Dessau, Geschichte der römischen Kaiserzeit. Band 2.1: Die Kaiser von Tiberius bis Vitellius, Berlin 1926.

W. Eck, Senatoren von Vespasian bis Hadrian. Prosopographische Untersuchungen mit Einschluß der Jahres- und Provinzialfasten der Statthalter, München 1970 (Vestigia, 13).

B. Edelmann-Singer, Koina und Concilia. Genese, Organisation und sozioökonomische Funktion der Provinziallandtage im römischen Reich, Stuttgart 2015.

P. Fabia, La Table Claudienne de Lyon, Lyon 1929. 
ders., A propos de la Table Claudienne, in: REA 33 (1931), S. 117-138.

D. Flach, Die Rede des Claudius De iure honorum Gallis dando, in: Hermes 101 (1973), S. 313-320.

E. Flaig, Tradition und Innovation. Kaiser Claudius und das römische Selbstverständnis, in: A. Heil/M. Korn et al. (Hrsg.), Noctes Sinenses. Festschrift für FritzHeiner Mutschler zum 65. Geburtstag, Heidelberg 2011, S. 287-293.

H. Freis, Die Integration der provinzialen Oberschicht im römischen Reich, in: U. Riemer/P. Riemer (Hrsg.), Xenophobie - Philoxenie. Vom Umgang mit Fremden in der Antike : Symposion vom 23./24. Mai 2002 in der Modernen Galerie, Saarbrücken, Stuttgart 2005 (Potsdamer altertumswissenschaftliche Beiträge, 7), S. 131-141.

H. Galsterer, Coloniae, DNP 3 (1997), Sp. 76-85.

ders., Municipium, DNP 8 (2000), Sp. 476-479.

M. Griffin, The Lyons Tablet and Tacitean Hindsight, in: CQ 32 (1982), 404-418.

dies., Claudius in Tacitus, in: CQ 40 (1990), S. 482-501.

H. Halfmann, Die Senatoren aus dem östlichen Teil des Imperium Romanum bis zum Ende des 2. Jahrhunderts n. Chr, Göttingen 1979 (Hypomnemata, 58).

E. G. Hardy, The speech of Claudius on the adlection of Gallic senators, in: The Journal of Philology 32 (1913), S. 79-95.

ders., Clavdivs and the Primores Galliae, in: CQ 8 (1914), S. 282-288.

W. Huß, Eine scherzhafte Bemerkung des Kaisers Claudius?, in: Historia 29 (1980), S. 250-255.

D. Kienast, W. Eck, M. Heil, Römische Kaisertabelle. Grundzüge einer römischen Kaiserchronologie, 6. vollst. überarb. und akt. Aufl., Darmstadt 2017.

H. Last, Rezension zu: Jérôme Carcopino, Points de vue sur l'imperialisme romain, Paris (Le-Divan) 1934 (Collection Saint-Germain-des-Prés, 12), in: JRS 24 (1934), S. 56-60.

B. Levick, Claudius, London 1990.

J. Malitz, Claudius - Der Prinzeps als Gelehrter, in: V. M. Strocka (Hrsg.), Die Regierungszeit des Kaisers Claudius (41-54 n. Chr). Umbruch oder Episode? : Internationales interdisziplinäres Symposion aus Anlass des hundertjährigen Jubiläums des Archäologischen Instituts der Universität Freiburg i. Br. am 16.-18. Februar 1991, Mainz 1994, S. 133-141.

S. J. V. Malloch, Hamlet without the prince? The Claudian Annals, in: A. J. Woodman (Hrsg.), The Cambridge companion to Tacitus, Cambridge 2009, S. 116-126.

J. B. Meister, Lachen in der Politik. Zur Funktion von Humor in der politischen Kommunikation des römischen Principats, in: Klio 96 (2014), S. 26-48.

F. Millar, The Emperor in the Roman World (31 BC - AD 337), Ithaca, NY 1977. 
N. P. Miller, The Claudian Table and Tacitus: a Reconsideration, in: RhM N. F. 99 (1956), S. 304-315.

T. Mommsen, Römisches Staatsrecht. Band I, 3. Aufl, Leipzig 1887.

F. Münzer, Die Verhandlungen über das Jus honorum der Gallier im Jahre 48, in: O. Hirschfeld (Hrsg.), Beiträge zur Alten Geschichte und Griechisch-Römischen Alterthumskunde. Festschrift zu Otto Hirschfelds sechzigstem Geburtstag, Berlin 1903, S. 34-44 (wiederabgedruckt in: M. Haake/A.-C. Harders [Hrsg.], Friedrich Münzer, Kleine Schriften, Stuttgart 2012, S. 193-203).

J. Osgood, Claudius Caesar. Image and Power in the Early Roman Empire, Cambridge 2011.

H. F. Pelham, The Emperor Claudius and the chiefs of the Aedui, in: CR 9 (1895), S. 441-443.

G. Perl, Die Rede des Kaisers Claudius für die Aufnahme römischer Bürger aus Gallia Comata in den Senat (CIL XIII 1668), in: Philologus 140 (1996), S. 114-138.

W. Riess, Die Rede des Claudius über das Ius Honorum der gallischen Notabeln: Forschungsstand und Perspektiven, in: REA 105 (2003), S. 211-249.

N. Schäfer, Die Einbeziehung der Provinzialen in den Reichsdienst in augusteischer Zeit, Stuttgart 2000, (HABES, 33).

U. Schillinger-Häfele, Claudius und Tacitus über die Aufnahme von Galliern in den Senat, in: Historia 14 (1965), S. 443-454.

dies., Gerechtigkeit für Claudius, in: Historia 38 (1989), S. 116-117.

E. Schönbauer, Zur Oratio Claudii de iure honorum Gallis dando, in: Iura 6 (1955), S. 160-169.

F. Staehelin, Kaiser Claudius, in: Ders., Reden und Vorträge, hrsg. v. W. Abt, Basel 1956, S. 147-171.

R. Syme, The provincial at Rome and Rome and the Balkans, 80 BC - AD 14, postum hrsg. von A. Birley, Exeter 1999.

R. J. A. Talbert, The Senate of Imperial Rome, Princeton, NJ 1984.

F. Vittinghoff, Zur Rede des Kaisers Claudius über die Aufnahme von "Galliern" in den römischen Senat, zuerst in: Hermes 82 (1954), S. 348-371, (wiederabgedruckt in: F. Vittinghoff/W. Eck [Hrsg.], Civitas Romana. Stadt und politischsoziale Integration im Imperium Romanum der Kaiserzeit, Stuttgart 1994, S. 299-321 [danach zitiert]).

K. Wellesley, Can you trust Tacitus?, in: G\&R N.F. 1 (1954), S. 13-33. 